\title{
ИССЛЕДОВАНИЕ СВОЙСТВ ТРЕХМЕРНОЙ КЛЕТОЧНОЙ МОДЕЛИ ОПУХОЛИ С ИСПОЛЬЗОВАНИЕМ НАНОФОТОСЕНСИБИЛИЗАТОРА В КАЧЕСТВЕ НОВОЙ ПРЕДКЛИНИЧЕСКОЙ МОДЕЛИ
}

\author{
Институт общей физики имени А. М. Прохорова Российской академии наук, Москва \\ 2 Научно-исследовательский центр автоматики университета Лотарингии, Нанси, Франция \\ Белорусский государственный университет, Минск, Белоруссия \\ ${ }^{4}$ Национальный исследовательский ядерный университет «МИФИ», Москва
}

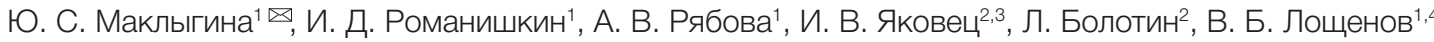

\begin{abstract}
Ввиду своих особенностей наночастицы (НЧ), состоящие из фрталоцианина алюминия (HЧ AlPC), являются перспективным фотосенсибилизатором. НЧ AІРc не флуоресцируют в свободной наноформе, слабо флуоресцируют в нормальной ткани, сильно - в опухолях и очень сильно - в макрофрагах. НЧ АІРс обладают уникальной особенностью приобретать способность к флуоресценции и фототоксичности в контакте с некоторыми биокомпонентами. При этом тип биокомпонентов, связывающихся с НЧ AІPc, влияет на интенсивность, время жизни и спектральное распределение флуоресценции. Целью работы было исследовать особенности захвата нанофотосенсибилизатора в 3D-моделях клеточных культур. Полученные данные демонстрируют захват HЧ AІPc клетками внутри ссрероида в течение первого часа по росту флуоресцентного сигнала. Обнаружена гетерогенность клеточных 3D-моделей по анализу изменения сигнала флуоресценции НЧ AІPc внутри сфероида. В результате лазерного облучения (двухфотонного возбуждения с $\lambda=780 / 390$ нм) наблюдали фотобличинг флуоресценции, который, вероятно, связан с деактивацией HЧ AIPc. Таким образом, созданная модель, состоящая из клеточной 3D-культуры с Hч AlPc, позволяет лучше оценивать метаболитические процессы в клетках, чем монослойные клеточные 2D-культуры. Кроме того, модель позволяет оценивать фотодинамический эффект в зависимости от фенотипичных свойств различных областей в гетерогенной 3D-структуре.
\end{abstract}

Ключевые слова: фрталоцианин алюминия, наночастицы, нанофотосенсибилизатор, многоклеточный опухолевый сфероид, лазерная сканирующая микроскопия

Финансирование: работа поддержана Министерством образования и науки Российской Федерации (соглашение RFMEFI61618X0096 № 14.616.21.0096 от 12.02.2018)

$\triangle$ Для корреспонденции: Юлия Сергеевна Маклыгина

ул. Вавилова, д. 38, г. Москва, 119991; us.samsonova@physics.msu.ru

Статья получена: 26.06.2018 Статья принята к печати: 23.10.2018

DOI: $10.24075 /$ vrgmu.2018.079

\section{A NOVEL SPHEROID MODEL FOR PRECLINICAL INTERCELLULAR NANOPHOTOSENSITIZER-MEDIATED TUMOR STUDY}

\author{
Maklygina YuS ${ }^{\circledR}$, Romanishkin ID¹, Ryabova AV¹, Yakavets IV ${ }^{2,3}$, Bolotin L², Loschenov VB ${ }^{1,4}$ \\ 'Prokhorov General Physics Institute of the Russian Academy of Sciences, Moscow \\ ${ }^{2}$ Centre de Recherche en Automatique de Nancy (CRAN), Université de Lorraine, France \\ ${ }^{3}$ Belarusian State University, Minsk, Belarus \\ ${ }^{4}$ National Research Nuclear University «MEPhl», Moscow
}

\begin{abstract}
Aluminum phthalocyanine nanoparticles (NP AIPC) possess the features that make them a promising photosensitizer. In particular, AIPc NPs do not fluoresce in free nanoform, fluoresce weakly in normal tissue, strongly in tumors and very strongly in macrophages. Also, such particles fluoresce and become phototoxic when contacting certain biocomponents. The type of biocomponents that bind to AIPc NPS defines intensity, lifetime, and spectral distribution of the fluorescence. This study aimed to investigate the peculiarities of nanophotosensitizer capturing in 3D models of cell cultures. The data obtained demonstrate that AIPC NPs are captured by cells inside the spheroid in the course of the first hour, as the fluorescent signal's growth shows. Having analyzed the fluctuations of the fluorescence signal of AIPc NPs inside a spheroid, we have also discovered that the cellular 3D models are heterogeneous. Laser irradiation (two-photon excitation at $\lambda=780 / 390 \mathrm{~nm}$ ) resulted in photobleaching of fluorescence, which is probably associated with AIPC NP deactivation. Thus, the created model comprised of a 3D cell culture and AIPC NPs provides a better insight into metabolic processes in cells than monolayer 2D cell cultures. Besides, the model allows to evaluate the photodynamic effect depending on phenotypic properties of various areas in the heterogeneous 3D-structure.
\end{abstract}

Keywords: aluminum phthalocyanine, nanoparticles, nanophotosensitizer, multicellular tumor spheroid, laser scanning microscopy Funding: the study was supported by the Ministry of Education and Science of the Russian Federation (Agreement RFMEFI61618X0096 \#14.616.21.0096 of February 12, 2018).

$\triangle$ Correspondence should be addressed: Yuliya S. Maklygina

Vavilova 38, Moscow, 119991; us.samsonova@physics.msu.ru

Received: 26.06.2018 Accepted: 23.10.2018

DOI: 10.24075/brsmu.2018.079 
Наночастицы (НЧ), в основе которых лежат молекулярные нанокристаллы фотосенсибилизаторов (ФС), являются многообещающими агентами для флуоресцентной диагностики (ФД) и фотодинамической терапии (ФДТ). Нанокристаллы фталоцианина алюминия (AIPC) обладают преимуществом над молекулярными ФС, используемыми в клиниках ввиду значительно более высокой селективности накопления наноразмерных материалов [1-4]. Более того, молекулы, из которых они состоят, способны флуоресцировать только в мономерной форме при взаимодействии с биологическими структурами, предоставляя таким образом достаточную для ФД эффективность детектирования [1, 2]. Тип взаимодействия, интенсивность, время жизни, а также спектр флуоресценции зависят от фенотипа взаимодействующих клеток. Интенсивность флуоресценции НЧ AIPC значительно выше в патологической ткани (воспаленной или злокачественной) по сравнению с нормальной [1, 2]. Более того, НЧ AlPc можно рассматривать как зонды для использования в тераностике, поскольку они обладают флуоресценцией и фотодинамической активностью.

Исследования in vitro новых противоопухолевых агентов, особенно ФС, в первую очередь опираются на исследование фототоксичности с использованием выделенных клеточных линий. Общепринятые двумерные клеточные культуры (2D-культуры) имеют быстрый неограниченный рост и не позволяют моделировать сложность и гетерогенность in vivo опухолей. Очевидно, что in vivo опухоли растут в трехмерной (3D) структуре со специфичной организацией и архитектурой, которую клеточный 2D-монослой не способен воспроизвести [57]. Клеточные 3D-культуры считаются более аккуратной и воспроизводимой моделью для осуществления исследования лекарственных препаратов in vitro. Эта модель обладает рядом признаков, характерных опухолям in vivo, таким как наличие внеклеточного матрикса, межклеточного взаимодействия, гипоксии, глубокого проникновения препаратов и сопротивления [8-10]. Следовательно, сфероидная in vitro модель является промежуточными этапом между 2D-исследованием in vitro и исследованием на животных моделях [11-13].

Целью работы было разработать модель, основанную на многоклеточных 3D-сфероидах, для исследования накопления и распределения HЧ AIPc.

\section{МАТЕРИАЛЫ И МЕТОДЫ}

Многоклеточные сфероиды выращивали путем засевания $10^{4}$ клеток HeLa в планшет с 96 колодцами, предварительно покрытыми 1\%-й агарозой. Среду в культуре клеток сфероида меняли каждые 2-3 суток. По достижению $140 \pm 20$ мкм в диаметре после 7 дней сорероиды использовали в эксперименте. В качестве ФС использовали НЧ фталоцианина алюминия, или НЧ AIPC (d 100 нм, c = 10 мкг/Мл). Исследование флуоресценции $\mathrm{AIPc}$ после различного времени инкубации производили методами лазерной сканирующей конфокальной микроскопии. Для микроскопии сфероиды промывали дважды предварительно нагретым натрий-фоссратным буфером (PBS). Все изображения получали при помощи лазерного сканирующего микроскопа LSM710-NLO (Zeiss; Германия). Использовали объектив $20 \times$ с числовой апертурой $(\mathrm{NA})=1.4$. ФС фрталоцианин алюминия (НИОПИК; Россия) готовили для исследования сфероидной модели. Поликристаллический порошок AIPC добавляли в дистиллированную воду в концентрации 1 мг/Мл. Полученную взвесь диспергировали в ультразвуковом гомогенизаторе SONOPLUS HD2070 (Bandelin; Германия) с насадкой KE76 (20 кГц, амплитуда 165 мкм) [2]. Используя многоугловой спектрометр динамического рассеяния света Photocor Complex (Photocor; Россия), определили, что средний диаметр частиц в водном коллоиде составлял 100-150 нм. Коллоид AIPc (в концентрации 10 мкг/мл) добавляли в среду с моделью сфероида для моделирования условий взаимодействия клеток опухоли с НЧ ФС. Основным свойством НЧ АІРс является способность к фотоактивации. Базовый коллоид HЧ AІPc не люминесцировал при возбуждении в полосу поглощения (на длине волны 633 нм и при двухфотонном возбуждении на 780 нм), т. е. нанокристаллы ФС в свободной форме не проявляли фотоактивности. Таким образом, коллоид HЧ AlPc изначально не был фотоактивным и не проявлял флуоресцентных свойств. Однако при взаимодействии HЧ AIPc с клетками в результате процессов метаболизма, происходящих в клетках, НЧ становятся фотоактивными $\left(\lambda_{\mathrm{f}} \sim 670\right.$ нм при возбуждении на $\lambda_{\text {ех }} \sim 633$ нм и двухфотонном нелинейном возбуждении на 780 нм для более глубокого сканирования среза).

Эксперимент состоял из следующих этапов (рис. 1):

1) В начале эксперимента 10 сфероидов перенесли на чашку Петри. Коллоид HЧ AIPc добавили к 10 сфероидам В концентрации 10 мкг/мл. Инкубировали ФС при $37^{\circ} \mathrm{C}$ в течение 15 мин в темноте.

2) В течение последующей инкубации автофлуоресценцию возбуждали лазером 488 нм, одновременно с этим флуоресценцию HЧ AIPc возбуждали лазером 633 нм в сканирующем лазерном микроскопе. Флуоресцентный сигнал переставал расти после 1 ч инкубации с НЧ.

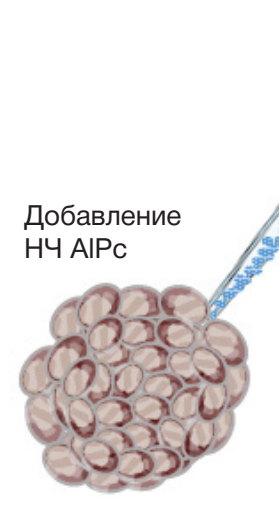

A

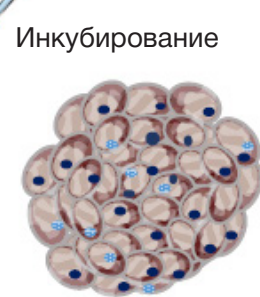

5

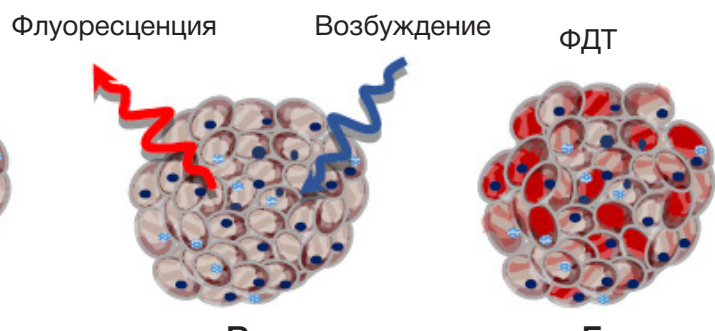

B

г

Рис. 1. Последовательная схема эксперимента со сфероидными моделями и НЧ AІРc 
3) После этого сфероиды промывали дважды с PBS и рассматривали в флуоресцентном микроскопе. Флуоресцентные изображения получали с поверхности сфероида с использованием 20х объектива. После инкубации НЧ ФС фотоактивность НЧ была достаточной для ФД и ФДТ. Исходя из этого, обнаруженные зоны интереса облучали лазером с длиной волны 780/390 нм (двухфотонное возбуждение) после анализа накопления ФС.

4) Лазерное возбуждение проводили на длине волны 780/390 нм (двухфотонное возбуждение). Продолжительность лазерного воздействия адаптировали для каждого сеанса облучения. Оценку фотодинамического эффекта осуществляли путем окрашивания акридином оранжевым (AO) для определения здоровых клеток (MolecularProbes ${ }^{\circledR}$; США) и бромистым этидием (EB) для определения мертвых клеток (MolecularProbes ${ }^{\oplus}$; CША). Сфероиды в PBS, предварительно отмытые от клеточной среды, для окрашивания инкубировали в растворе красителей в течение 5 мин. Окрашенные сфероиды из планшета с 96 лунками для in vitro культур переносили на чашки Петри (толщина стекла 0,17 мм) с раствором PBS. Распределение фрлуоресцентного сигнала AO/EB исследовали методами конфокальной микроскопии. Возбуждение флуоресценции АО производили лазером на длине волны 488 нм, его же флуоресценцию регистрировали в диапазоне длин волн 495-545 нм. Возбуждение флуоресценции ЕВ производили лазером на длине волны 561 нм, его же флуоресценцию регистрировали в диапазоне 580-690 нм. В результате получили фрлуоресцентные изображения АО (зеленый) и ЕВ (красный) в режиме проходящего света. Этот пошаговый подход позволил моделировать условия взаимодействия клеток опухоли с НЧ ФС в первый час и процессы ФД и ФДТ с НЧ AlPc in vivo.

\section{РЕЗУЛЬТАТЬ}

Захват HЧ AlPc оценивали в течение 1 ч. Значительное накопление наблюдали первые 30 мин (рис. 2А-В). После
40 мин инкубации фрлуоресцентный сигнал достиг плато без значительного дальнейшего изменения (рис. 2Г-Е). Усиление фллуоресценции НЧ AIPc в пространстве и времени позволило отслеживать распределение ФС. Первые 15 мин аккумуляцию HЧ AІPc можно было наблюдать В периферических регионах. Именно периферические клетки имели доступ к НЧ и в первую очередь принимали участие в эндоцитозе. Только после 15 мин инкубации начали образовываться первые участки захвата НЧ. С течением времени они быстро неупорядоченно росли в центр ссрероида (рис. 2В, Г). Непотревоженный участок при этом уменьшился до одной области с минимальным захватом НЧ в центре (рис. 2Д). Временная и пространственная динамика захвата HЧ AIPc, описанная выше, может быть объяснена гетерогенностью клеток в 3D-модели по метаболическим процессам и фенотипам. Иначе, захват Hч AIPc наблюдался бы как однородный на периферии с небольшим концентрическим спадом в сторону центра сфероида.

Численная оценка захвата ФС в различных участках была получена за счет записи спектров флуоресценции (рис. 3). Перед началом анализа стоит ввести величину, называемую эквивалентным диаметром, которая в условиях неидеальной сферичности определяется как диаметр круга в 150 мкм (средний диаметр ссрероида). Работу вели, предполагая, что площадь сфероида имеет то же значение, что и площадь поперечного сечения сфероида. Таким образом, полный флуоресцентный сигнал с участка был оцифрован и определены вклады от автофлуоресценции и флуоресценции НЧ АІРc (рис. ЗА, Б). Сигнал автофлуоресценции измеряли в диапазоне 430-630 нм при возбуждении лазерным излучением с длиной волны 488 нм. Максимум флуоресценции HЧ AIPC имеет длину волны 670 нм при возбуждении лазерным излучением с длиной волны 633 нм (рис. 3). Анализ спектров от концентрических участков среза показал, что захват HЧ AІPс уменьшается с ростом автослуоресценции от периферии к центру сфероида (рис. ЗГ).
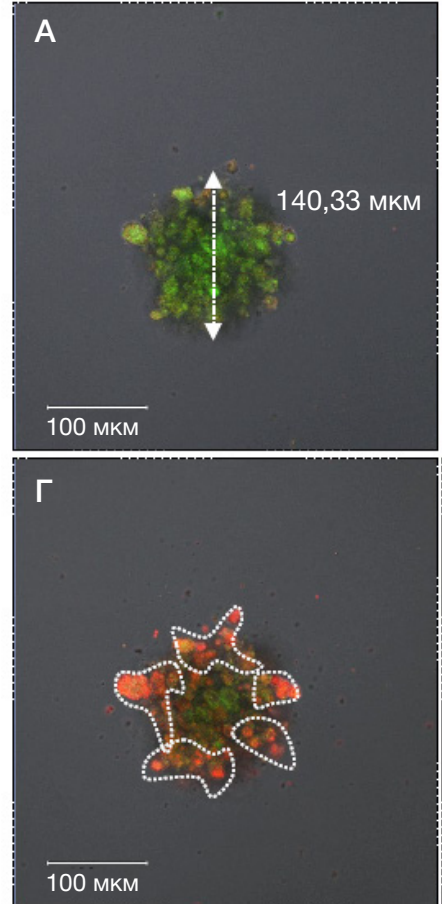
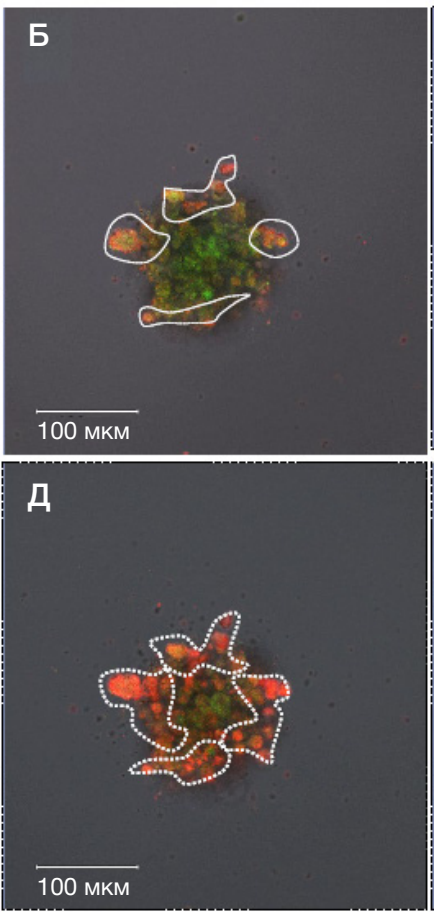
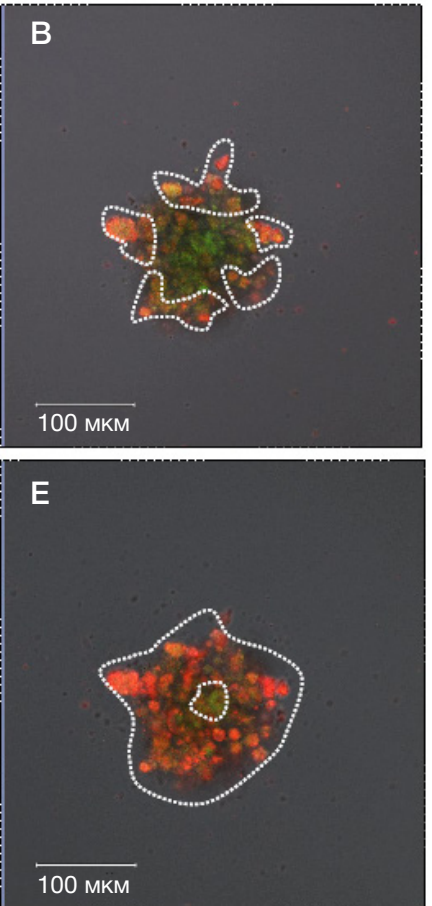

Рис. 2. Изображение разгорания флуоресценции НЧ AІPc с течением времени. Возбуждение автофлуоресценции (показано зеленым) с $\lambda_{\text {ех } \sim} 488$ нм и флуоресценции HЧ AІPс (показано красным) с $\lambda_{\text {ex }} \sim 633$ нм: 15 мин (А); 20 мин (Б); 30 мин (В); 40 мин (Г); 50 мин (Д); 1 ч (Е) 
Распределение захвата НЧ ФС с учетом только флуоресцентного сигнала было представлено в виде четырех сечений для удобного восприятия (рис. 4), что также демонстрирует максимум захвата ФС на периферии с локальным минимумом в центре.

\section{ОБСУЖДДНИЕ РЕЗУЛЬТАТОВ}

Оценка способности к проникновению вглубь сфероида и фототоксичность НЧ AІPс были проверены методом конфокальной лазерной микроскопии. Полученное разнообразие захвата НЧ в различных участках сфероида свидетельствует о гетерогенности сфероидной модели по фенотипу клеток. Это предположение подтверждается разницей в фототоксическом эффекте в различных участках сфероида, обусловленной наличием кислорода. С этой точки зрения, данная модель для исследования захвата и фотоиндуцированной токсичности HЧ AIPC очень схожа с опухолями in vivo [14-15]. Такой результат можно объяснить различием в метаболитических процессах в клетках. Действительно, согласно предыдущим исследованиям, апоптотическое ядро начинает формироваться в сфероидах диаметром приблизительно 150-200 мкм [16]. Аналогично опухолям in vivo многоклеточные сфероиды включают гипоксическую и апоптотическую/некротическую области, возникающие как результат формирования кислородного и питательного градиентов. Стоит заметить, что в сфероидах гипоксия возникает постепенно по мере роста сфероида [17]. Таким образом, наличие градиента захвата HЧ AIPc может
A

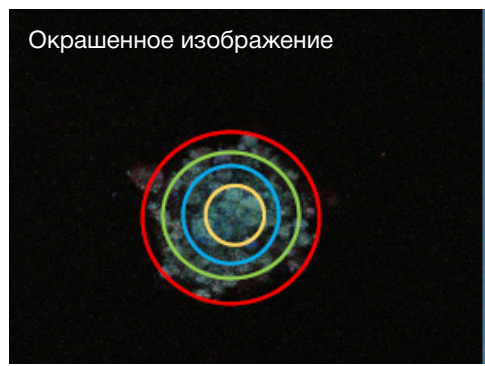

Б

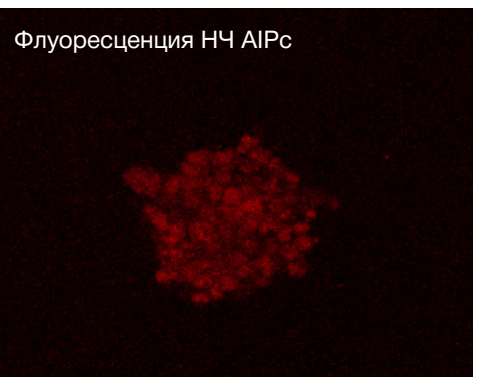

\section{B}

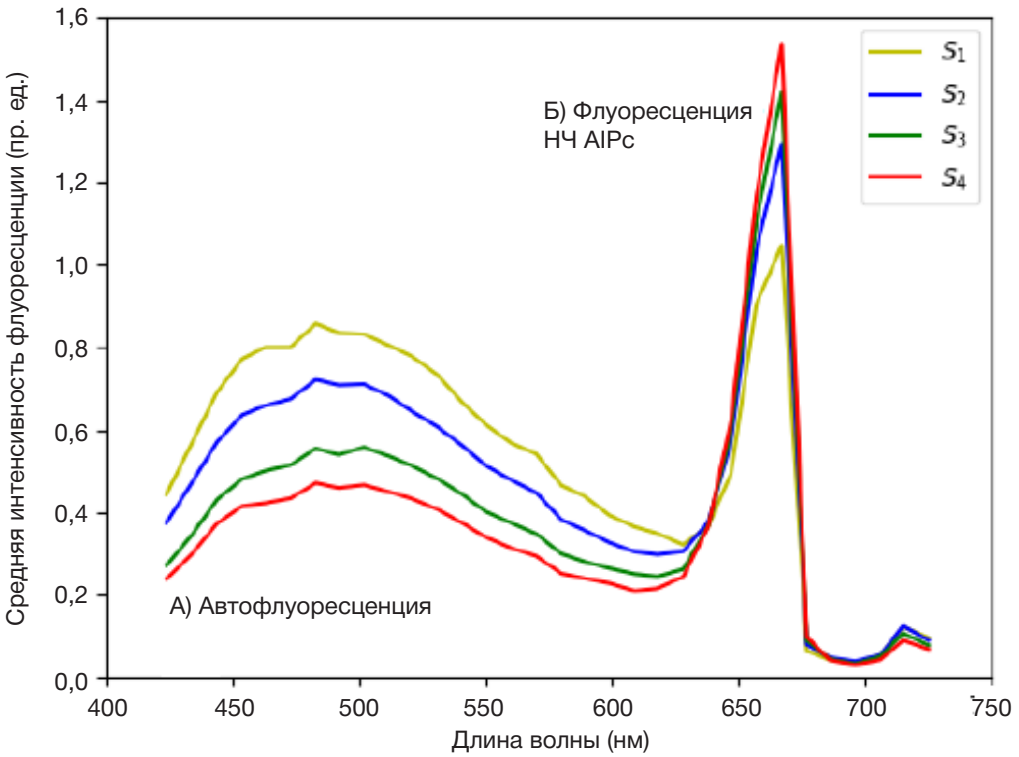

Рис. 3. Численное разделение сигналов: (А) флуоресцентное изображение, переведенное в RGB цветовую палитру; (Б) распределение флуоресценции НЧ AlPc; (B) спектры флуоресценции с цветом кривой, соответствующим цвету выделенной области. Спектры нормированы на площадь поверхности каждой области

A

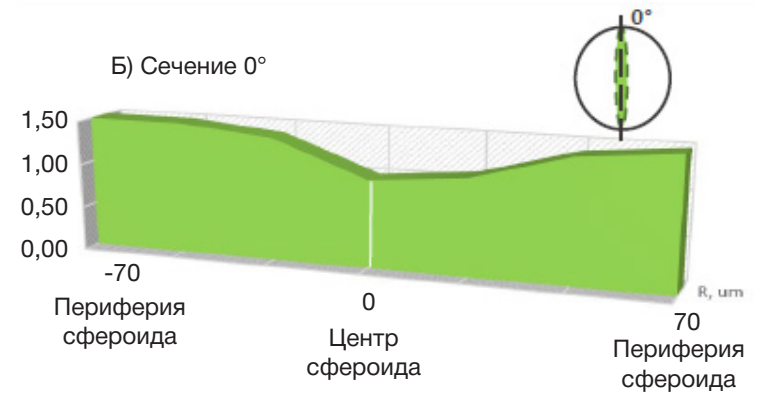

$\Gamma$

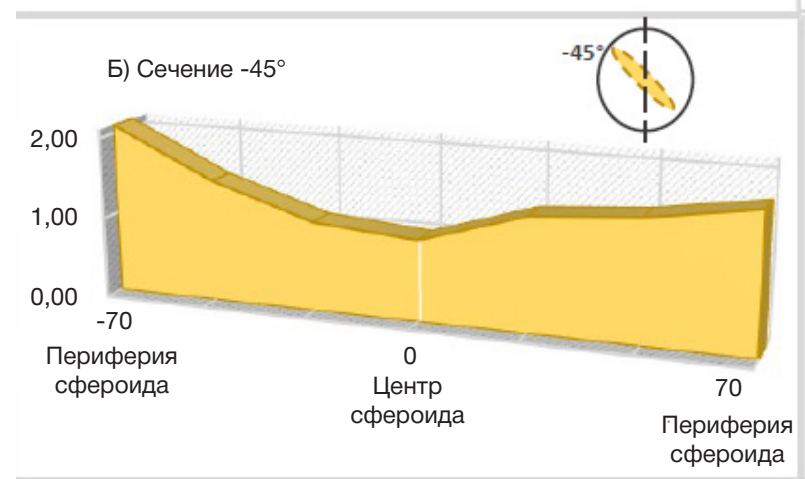

Б

Б) Сечение $90^{\circ}$

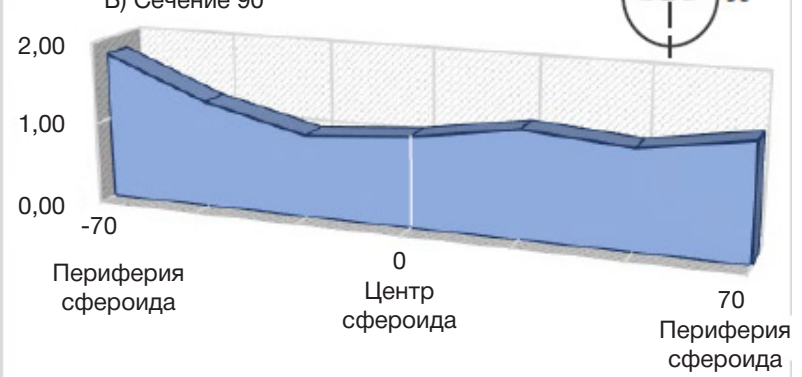

B

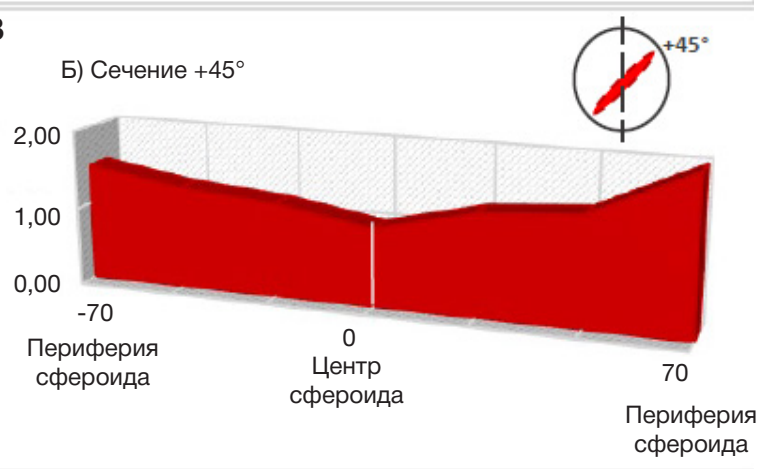

Рис. 4. Графическое представление захвата НЧ AІРс в четырех сечениях сфероида: (А) $0^{\circ}$; (Б) 90; (В) $45^{\circ}$; (Г) $-45^{\circ}$. Значения рассчитаны только с учетом флуоресценции ФС $\lambda$ 670 нм $\left(\lambda_{\text {ех }} \sim 633\right.$ нм), без автофлуоресценции клеток 
быть объяснено существованием градиента питательных вешеств и различий в фенотипе в клетках 3D-модели. Степень доступности молекулярного кислорода в различных участках можно оценить по скорости спада флуоресцентного сигнала во время фотодинамического облучения с тем условием, что фототоксичность зависит только от наличия молекулярного кислорода. Фотовоздействие приводит к переносу энергии в результате тушения фрлуоресценции ФС, а также провоцирует производство активных форм кислорода, приводящих к гибели клеток. Участки со значительным фотодинамическим эффектом были определены путем сравнения флуоресценции HЧ AIPc до и после сеанса ФДТ. Анализируя участки сфероида, можно заметить, что остаточный сигнал флуоресценции ФС наблюдался только в центре, в то время как в остальных областях он отсутствовал (рис. 5). Это может быть связано с гетерогенной структурой сфероида, с различной доступностью глубоких участков для облучающего света и с различной пролиферативной активностью клеток. В частности, отсутствие молекулярного кислорода в центральной области сфероида может приводить $\mathrm{k}$ ограниченному фотодинамическому воздействию с частичным спадом флуоресценции. Таким образом, градиент кислорода в сфероидах может быть косвенно оценен в ходе анализа эффектов фототоксичности ФС. Он также лежит в основе свойств опухолей in vivo, таких как гипоксия.

Фототоксичность была оценена по жизнеспособности клеток сфероидов после окрашивания и выявления живых и мертвых клеток. Это было продемонстрировано в сравнении с окраской первичных сфероидов и выявлением живых клеток (рис. 6А). Живые клетки были обнаружены после ФДТ только в центре сфероида (рис. 6Б), мертвые клетки занимали основной объем (рис. 6Б). Окрашивание, характеризующее жизнеспособность клеток, равномерно по всему объему 3D-модели, поскольку не учитывает метаболических процессов, происходящих в клетках в различных слоях сфероида.

Высокое накопление ФС и глубина проникновения являются самыми важными характеристиками для оценки противоопухолевой эффективности препарата. Эти характеристики нужно учитывать при исследовании новых ФС. Более того, основной причиной неполного уничтожения опухоли служит неоднородное распределение ФС. Поэтому особенно важно комплексное исследование пространственного и временного процесса распределения ФС в тканях. Сфероидные модели позволяют моделировать проникновение и внутриопухолевый транспорт НЧ ФС. На сегодняшний день было исследовано большое количество НЧ для эфффективной и целевой доставки ФС. Недостатком некоторых наноносителей является ограниченное проникновение, но можно предположить, что размер НЧ тоже имеет большое значение [18-19]. Таким образом, можно заключить, что НЧ AІРс являются многообещающими ФС с высокой фототоксичностью, которые позволяют косвенно оценить распределения кислорода в тканях, клеточный фенотип и проводить анализ метаболических процессов в клетках. В то же время по оценке фллуоресценции AIPc видно, что многоклеточные 3D-модели обладают такими характерными признаками опухолей in vivo, как межклеточное взаимодействие, гипоксия, градиент кислорода и градиент питательных веществ. Мы предполагаем, что сфероидная модель in vitro является хорошей платформой для исследования наноразмерных лекарств, включая ФС, до испытаний
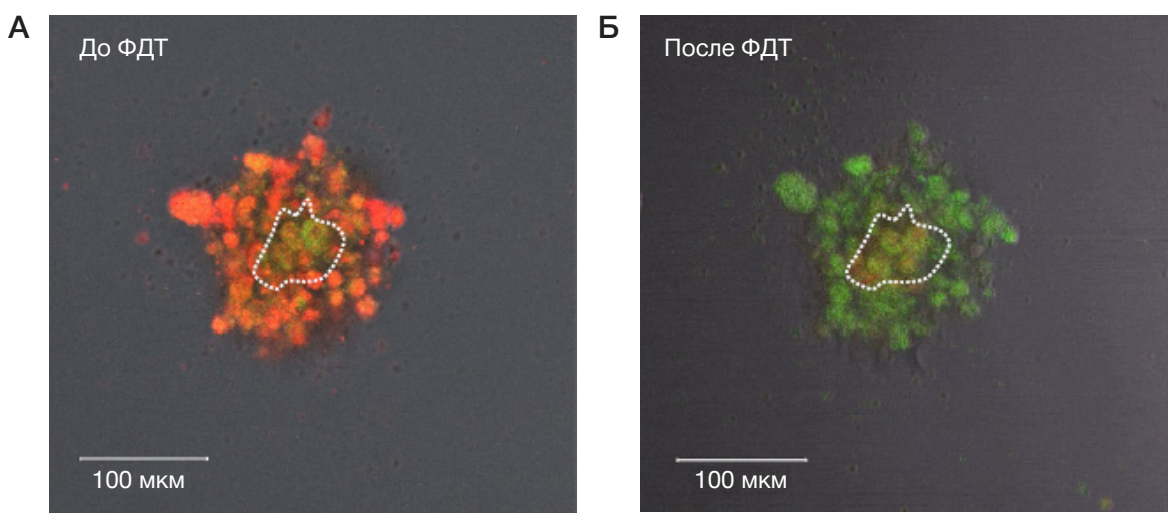

Рис. 5. Сравнение флуоресценции AІРc до ФДТ (А) и после ФДТ (Б). Возбуждение автофлуоресценции на $\lambda \sim 488$ нм, возбуждение НЧ AIPc на $\lambda \sim 633$ нм

A

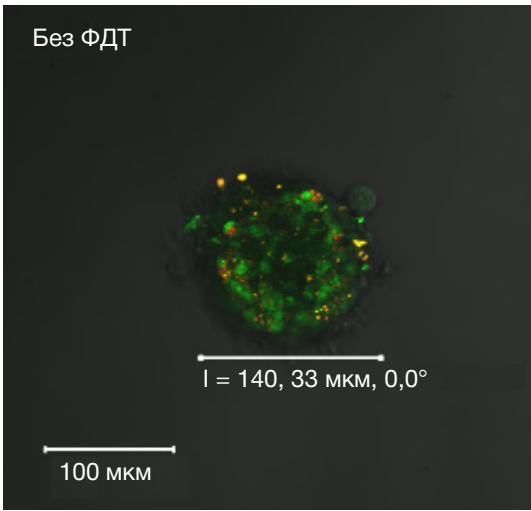

Б

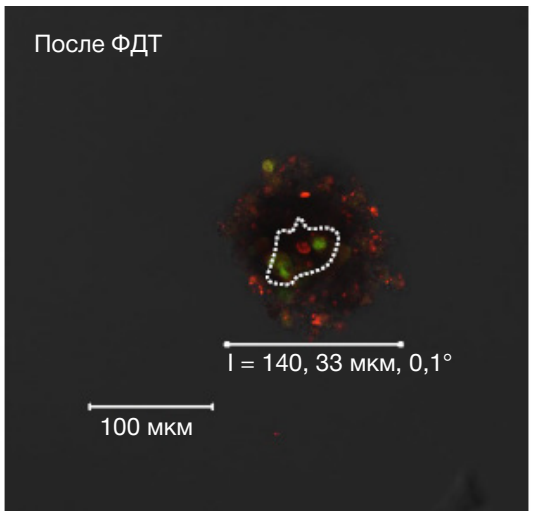

Рис. 6. Анализ жизнеспособности клеток после ФДТ, окраска акридином оранжевым (зеленый цвет - живые клетки) (А) и бромистым этидием (красный цвет - мертвые клетки) (Б). Возбуждение флуоресценции АО проводили при воздействии лазерного излучения с длиной волны 488 нм, возбуждение флуоресценции ЕВ проводили при воздействии лазерного излучения с длиной волны $561 \mathrm{HM}$ 
на животных моделях, в которых необходимо учитывать также иммунный ответ [20-24].

\section{ВЫВОДЫ}

В работе продемонстрировано преимущество использования H4 AlPC в качестве ФС и многофункционального флуоресцентного зонда. HЧ AIPc имеют достаточную способность накапливаться, распределяться и проникать в сфероиды. С помощью микроскопических методик показано, что, несмотря на достаточное накопление, фотодинамическая активность НЧ AІPc зависит от биоокружения. В особенности НЧ AІPc позволили оценить гетерогенность опухолевой модели и косвенно определить концентрацию кислорода, фенотип клеток, составляющих 3D-модель, а также метаболические процессы в клетках. Это одни из самых важных параметров для специфической местной нанофототераностики. Полученные результаты могут быть полезны для исследования других клеточных моделей, например ко-культурных сфероидов, которые учитывают также иммунный ответ.

\section{Литература}

1. Breymayer J, Rück A, Ryabova AV, Loschenov VB, Steiner RW. Fluorescence Investigation of the Effect of Monocytes/ Macrophages and Skin Cells on Aluminium Phthalocyanine Nanoparticles. Journal Photodiagnosis and Photodynamic Therapy. 2014; 11(3): 380-90.

2. Vasilchenko SYu, Volkova Al, Ryabova AV, Loschenov VB, Konov VI, Mamedov AA et al. Application of aluminum phthalocyanine nanoparticles for fluorescent diagnostics in dentistry and skin autotransplantology. J Biophoton. 2010; 3 (5-6): 336-46.

3. Chiarante N, García Vior MC, Awruch J, Marino J, Roguin LP. Phototoxic action of a zinc (II) phthalocyanine encapsulated into poloxamine polymeric micelles in 2D and 3D colon carcinoma cell cultures. J Photochem Photobiol B. 2017; 170: 140-51.

4. Waite CL, Roth CM. Nanoscale drug delivery systems for enhanced drug penetration into solid tumors: current progress and opportunities. Crit Rev Biomed Eng. 2012; 40: 21-41.

5. Kumari P, Jain S, Ghosh B, Zorin V, Biswas S. PolylactideBased Block Copolymeric Micelles Loaded with Chlorin e6 for Photodynamic Therapy: In Vitro Evaluation in Monolayer and 3D Spheroid Models. Mol Pharm. 2017 Nov 6; 14 (11): 3789-800.

6. Patel NR, Aryasomayajula B, Abouzeid AH, Torchilin VP. Cancer cell spheroids for screening of chemotherapeutics and drugdelivery systems. Ther Deliv. 2015; (6): 509-20.

7. Khanna S, Bhatt AN, Dwarakanath BS. Chapter 11 - multicellular spheroid: 3-D tissue culture model for cancer research A2. In: Ashish S Verma, Singh A, editors. Animal Biotechnology. San Diego: Academic Press, 2014; 195-210.

8. Kimlin LC, Casagrande G, Virador VMю In vitro three-dimensional (3D) models in cancer research: an update. Mol Carcinog. 2013; (52): 167-82.

9. Baker BM, Chen CS. Deconstructing the third dimension: how 3D culture microenvironments alter cellular cues. J Cell Sci. 2012; (125): 3015-24.

10. Wartenberg $\mathrm{M}$ et al. Regulation of the multidrug resistance transporter P-glycoprotein in multicellular tumor spheroids by hypoxia-inducible factor (HIF-1) and reactive oxygen species. FASEB J. 2003; (17): 503-5.

11. Evans CL. Three-dimensional in vitro cancer spheroid models for photodynamic therapy: strengths and opportunities. Front Phys. 2015; 3 (15): 1-7.

12. Yakavets I, Yankovsky I, Millard M, Lamy L, Lassalle HP, Wiehe A et al. The alteration of temoporfin distribution in multicellular tumor spheroids by $\beta$-cyclodextrins. Int J Pharm. 2017; 529 (1-2): 56875.

13. Ricketts KP, Cheema U, Nyga A, Castoldi A, Guazzoni C, Magdeldin T et al. A 3D in vitro cancer model as a platform for nanoparticle uptake and imaging investigations. 2014; 10 (19): 3954-61.

14. Kapinus VN, Kaplan MA, Yaroslavtseva-Isayeva EV, Spichenkova IS. Photodynamic therapy for head and neck basal cell skin cancer with additional interstitial laser irradiation. Biomedical Photonics. 2017; 6 (4): 20-6.

15. Abraham JA, Golubnitschaja O. Time for paradigm change in management of hepatocellular carcinoma: is a personalized approach on the horizon? Per Med. 2016; 13 (5): 455-67.

16. Hirschhaeuser F, Menne H, Dittfeld C, West J, Mueller-Klieser W, Kunz-Schughart LA. Multicellular tumor spheroids: an underestimated tool is catching up again. J Biotechnol. 2010; (148): 3-15.

17. Josef LB, Boyle RW. Unique diagnostic and therapeutic roles of porphyrins and phthalocyanines in photodynamic therapy, imaging and theranostics. Theranostics. 2012; (2): 916-66.

18. Franken NAP, Rodermond HM, Stap J, Haveman J, van Bree C. Clonogenic assay of cells in vitro. Nat Protoc. 2006; (1): 2315-9.

19. Dreher MR, Liu W, Michelich CR, Dewhirst MW, Yuan F, Chilkoti A Tumor vascular permeability, accumulation, and penetration of macromolecular drug carriers. J Natl Cancer Inst. 2006; (98): 335-44.

20. Dobiasova M, Urbanova Z, Samanek M Relations between particle size of HDL and LDL lipoproteins and cholesterol esterification rate. Physiol Res Acad Sci Bohemoslov. 2005; (54): 159-65.

21. Kitamura T, Qian BZ, Pollard JW. Immune cell promotion of metastasis. Nat Rev Immunol. 2015; 15 (2): 73-86.

22. Kumar V, Patel S, Tcyganov E, Gabrilovich DI. The Nature of Myeloid-Derived Suppressor Cells in the Tumor Microenvironment. Trends Immunol. 2016; 37 (3): 208-20.

23. Long L, Yin M, Min W. 3D Co-culture System of Tumor-associated Macrophages and Ovarian Cancer. Cells Bio Protoc. 2018; 8 (8).

24. Sherman H, Gitschier HJ, Rossi AE. A novel three-dimensional immune oncology model for high-throughput testing of tumoricidal activity. Front Immunol. 2018 Apr 23; (9): 857.

\section{References}

1. Breymayer J, Rück A, Ryabova AV, Loschenov VB, Steiner RW. Fluorescence Investigation of the Effect of Monocytes/ Macrophages and Skin Cells on Aluminium Phthalocyanine Nanoparticles. Journal Photodiagnosis and Photodynamic Therapy. 2014; 11(3): 380-90.

2. Vasilchenko SYu, Volkova Al, Ryabova AV, Loschenov VB, Konov VI, Mamedov AA et al. Application of aluminum phthalocyanine

nanoparticles for fluorescent diagnostics in dentistry and skin autotransplantology. J Biophoton. 2010; 3 (5-6): 336-46.

3. Chiarante N, García Vior MC, Awruch J, Marino J, Roguin LP. Phototoxic action of a zinc (II) phthalocyanine encapsulated into poloxamine polymeric micelles in 2D and 3D colon carcinoma cell cultures. J Photochem Photobiol B. 2017; 170: 140-51.

4. Waite CL, Roth CM. Nanoscale drug delivery systems for 
enhanced drug penetration into solid tumors: current progress and opportunities. Crit Rev Biomed Eng. 2012; 40: 21-41.

5. Kumari P, Jain S, Ghosh B, Zorin V, Biswas S. PolylactideBased Block Copolymeric Micelles Loaded with Chlorin e6 for Photodynamic Therapy: In Vitro Evaluation in Monolayer and 3D Spheroid Models. Mol Pharm. 2017 Nov 6; 14 (11): 3789-800.

6. Patel NR, Aryasomayajula B, Abouzeid AH, Torchilin VP. Cancer cell spheroids for screening of chemotherapeutics and drugdelivery systems. Ther Deliv. 2015; (6): 509-20.

7. Khanna S, Bhatt AN, Dwarakanath BS. Chapter 11 - multicellular spheroid: 3-D tissue culture model for cancer research A2. In: Ashish S Verma, Singh A, editors. Animal Biotechnology. San Diego: Academic Press, 2014; 195-210.

8. Kimlin LC, Casagrande G, Virador VMю In vitro three-dimensional (3D) models in cancer research: an update. Mol Carcinog. 2013; (52): 167-82

9. Baker BM, Chen CS. Deconstructing the third dimension: how 3D culture microenvironments alter cellular cues. J Cell Sci. 2012 (125): 3015-24.

10. Wartenberg $\mathrm{M}$ et al. Regulation of the multidrug resistance transporter P-glycoprotein in multicellular tumor spheroids by hypoxia-inducible factor (HIF-1) and reactive oxygen species. FASEB J. 2003; (17): 503-5.

11. Evans CL. Three-dimensional in vitro cancer spheroid models for photodynamic therapy: strengths and opportunities. Front Phys. 2015; 3 (15): 1-7.

12. Yakavets I, Yankovsky I, Millard M, Lamy L, Lassalle HP, Wiehe A et al. The alteration of temoporfin distribution in multicellular tumor spheroids by $\beta$-cyclodextrins. Int J Pharm. 2017; 529 (1-2): 56875.

13. Ricketts KP, Cheema U, Nyga A, Castoldi A, Guazzoni C, Magdeldin T et al. A 3D in vitro cancer model as a platform for nanoparticle uptake and imaging investigations. 2014; 10 (19): 3954-61.
14. Kapinus VN, Kaplan MA, Yaroslavtseva-Isayeva EV, Spichenkova IS. Photodynamic therapy for head and neck basal cell skin cancer with additional interstitial laser irradiation. Biomedical Photonics. 2017; 6 (4): 20-6.

15. Abraham JA, Golubnitschaja O. Time for paradigm change in management of hepatocellular carcinoma: is a personalized approach on the horizon? Per Med. 2016; 13 (5): 455-67.

16. Hirschhaeuser F, Menne H, Dittfeld C, West J, Mueller-Klieser W, Kunz-Schughart LA. Multicellular tumor spheroids: an underestimated tool is catching up again. J Biotechnol. 2010; (148): 3-15

17. Josef LB, Boyle RW. Unique diagnostic and therapeutic roles of porphyrins and phthalocyanines in photodynamic therapy, imaging and theranostics. Theranostics. 2012; (2): 916-66.

18. Franken NAP, Rodermond HM, Stap J, Haveman J, van Bree C. Clonogenic assay of cells in vitro. Nat Protoc. 2006; (1): 2315-9.

19. Dreher MR, Liu W, Michelich CR, Dewhirst MW, Yuan F, Chilkoti A. Tumor vascular permeability, accumulation, and penetration of macromolecular drug carriers. J Natl Cancer Inst. 2006; (98): 335-44.

20. Dobiasova M, Urbanova Z, Samanek M Relations between particle size of HDL and LDL lipoproteins and cholesterol esterification rate. Physiol Res Acad Sci Bohemoslov. 2005; (54): 159-65.

21. Kitamura T, Qian BZ, Pollard JW. Immune cell promotion of metastasis. Nat Rev Immunol. 2015; 15 (2): 73-86.

22. Kumar V, Patel S, Tcyganov E, Gabrilovich DI. The Nature of Myeloid-Derived Suppressor Cells in the Tumor Microenvironment. Trends Immunol. 2016; 37 (3): 208-20.

23. Long L, Yin M, Min W. 3D Co-culture System of Tumor-associated Macrophages and Ovarian Cancer. Cells Bio Protoc. 2018; 8 (8).

24. Sherman H, Gitschier HJ, Rossi AE. A novel three-dimensional immune oncology model for high-throughput testing of tumoricidal activity. Front Immunol. 2018 Apr 23; (9): 857. 